\title{
Estimating the real world daily usage and cost for exenatide twice daily and liraglutide in Germany, the Netherlands, and the UK based on volumes dispensed by pharmacies
}

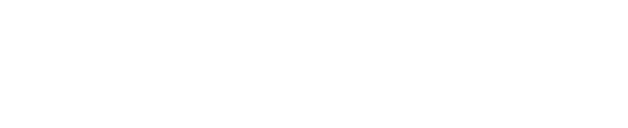

\author{
Amanda L McDonell' \\ Urpo Kiiskinen ${ }^{2}$ \\ Danielle C Zammit ${ }^{3}$ \\ Robert W Kotchie' \\ Per-Olof Thuresson ${ }^{3}$ \\ Claudia Nicolay ${ }^{4}$ \\ Thomas Haslam' \\ Michiel Bruinsma ${ }^{5}$ \\ Anne-Jeanine Janszen-Van \\ Oosterhout ${ }^{6}$ \\ Thorsten Otto ${ }^{4}$ \\ 'IMS Health, London, UK; ${ }^{2}$ Eli Lilly \\ and Company, Helsinki, Finland; \\ ${ }^{3}$ IMS Health, Basel, Switzerland; ${ }^{4} \mathrm{Eli}$ \\ Lilly and Company, Bad Homburg, \\ Germany; 5 IMS Health, Rotterdam, \\ the Netherlands; 'Eli Lilly Nederland, \\ Houten, the Netherlands
}

Correspondence: Amanda L McDonell IMS Health, 210 Pentonville Road, London, NI 9JY, UK

Tel +44203075 4848

Fax +44 2030755900

Email amcdonell@uk.imshealth.com
Background: Glucagon-like peptide-1 (GLP-1) receptor agonists are indicated for improvement of glycemic control in adults with type 2 diabetes. Cost is one aspect of treatment to be considered, in addition to clinical benefits, when selecting optimal therapy for a patient. The objective of this study was to estimate the average dose usage and real world daily cost of the GLP-1 receptor agonists, exenatide twice daily and liraglutide once daily, in Germany, the Netherlands, and the UK.

Methods: Administrative databases were used to source the data from longitudinal records of dispensed prescriptions. Data were extracted from the IMS Longitudinal Prescription database which captures details of prescriptions dispensed in pharmacies. Information on the dispensed quantity of each product was used to estimate average daily usage per patient. Daily dose usage was multiplied by the public price per unit to estimate daily cost.

Results: The dispensed volume in Germany corresponded to a mean dispensed daily dose of $16.81 \mu \mathrm{g}$ for exenatide twice daily and $1.37 \mathrm{mg}$ for liraglutide (mean daily cost $€ 4.02$ and $€ 4.54$, respectively). In the Netherlands, average dispensed daily doses of $17.07 \mu \mathrm{g}$ and $1.49 \mathrm{mg}$ were observed for exenatide twice daily and liraglutide (mean daily cost $€ 3.05$ and $€ 3$.97, respectively). In the UK, the mean dispensed volume corresponded to a daily usage of $20.49 \mu \mathrm{g}$ for exenatide twice daily and $1.50 \mathrm{mg}$ for liraglutide (mean daily cost $£ 2.53$ and $£ 3.28$, respectively).

Conclusion: Estimates of average daily dispensed doses of GLP-1 receptor agonists derived from pharmacy data in real world settings corresponded to the dosing recommendation of the summaries of product characteristics. Nevertheless, the mean daily cost of exenatide twice daily was lower than that of liraglutide in Germany, the Netherlands, and the UK. Such estimates can be used to inform health care decision-makers on the real world usage and cost of medications effective in achieving glycemic control in patients with type 2 diabetes.

Keywords: type 2 diabetes, exenatide twice daily, liraglutide, dosage, cost, real world

\section{Introduction}

Type 2 diabetes results in hyperglycemia that can result in serious complications. Current World Health Organization estimates place the number of people with diabetes globally at 346 million, 90\% of whom suffer from type 2 diabetes; this number is projected to grow in the future, with increased health care expenditures as a consequence. ${ }^{1}$ The International Diabetes Federation estimates the health expenditure for diabetes to be 25.2 billion (2010 Int\$) in Germany, 3.4 billion (2010 Int\$) in the Netherlands, and 6.5 billion (2010 Int\$) in the UK. ${ }^{2}$ CODE-2 (the Cost of Diabetes in Europe - Type II study) estimated that antidiabetes medications accounted for 
only $7 \%$ of direct health care costs for individuals with this disease, with hospitalizations, ambulatory costs, and other drugs accounting for $55 \%, 18 \%$, and $21 \%$, respectively. ${ }^{3}$ Drug costs differ depending on the physician's clinical choices, including the dose prescribed.

The first step in diabetes management is lifestyle intervention. ${ }^{4}$ If this step is not sufficient to maintain glucose control, the next step is to initiate treatment with an oral glucose-lowering drug, most often metformin, proceeding to addition of second-line and third-line therapeutic agents if necessary. Exenatide twice daily $\left(\right.$ Byetta $^{\circledR}$, AstraZeneca, London, UK) and liraglutide (Victoza ${ }^{\circledR}$, Novo Nordisk, Bagsvaerd, Denmark) are the third-line choices of therapy most often considered by European health care systems based on treatment guidelines. ${ }^{5}$ They both belong to the class of glucagon-like peptide-1 (GLP-1) receptor agonists and have similar mechanisms of action. Several clinical trials have investigated the efficacy of exenatide twice daily and liraglutide in patients with type 2 diabetes. A more recent study compared liraglutide $1.8 \mathrm{mg}$ once daily with exenatide $10 \mu \mathrm{g}$ twice daily, ${ }^{6}$ and showed that there are differences between agents in the GLP-1 receptor agonist class. Overall, liraglutide $1.8 \mathrm{mg}$ once daily was found to have better efficacy in terms of improving glycemic control and better tolerability when compared with exenatide $10 \mu \mathrm{g}$ twice daily. ${ }^{6}$ Both therapies are initiated at a starting dose (Figure 1) according to their respective Summary of Product Characteristics. ${ }^{7,8}$ The exenatide twice daily dose can be increased once, whereas liraglutide may be titrated upward twice if needed to achieve better glycemic control.

CODE-2 demonstrated the significant financial burden has diabetes places on health care systems in Europe.
Annual direct medical costs for people with type 2 diabetes have been reported to account for $6.5 \%, 1.6 \%$, and $2.5 \%$ of the total direct medical health care expenditure in Germany, the Netherlands, and the UK, respectively. ${ }^{3}$ It is thus essential for the relevant stakeholders to allocate resources in the most efficient manner, with consideration of decisions that would contribute to improved glycemic control and a consequently lower cost burden to the health care system. Given that the first lines of antidiabetic therapy are often generic (eg, metformin and sulfonylurea), health care budget decision-makers may shift their focus to second-line and third-line agents in the treatment algorithm when considering where to reduce expenditures. Being more expensive, thirdline agents, such as exenatide twice daily and liraglutide, are likely to come under close scrutiny.

In the process of health technology assessment, the cost of drug therapy is part of the cost associated with disease management. The cost of drug therapy depends on how much medication is used. However, it is very difficult to predict the actual real world usage of these therapies, including the preferred dose, based only on clinical studies. While clinical trials demonstrate efficacy at indicated doses, the effectiveness observed in clinical practice depends on the actual dosages used. In order to understand the budgetary consequences of such decisions, the estimated cost of diabetes medication should be based on dosages used in real life settings. The real world dosage is likely to be different from that in the clinical recommendations. Given the described titration scheme of these therapies and the consequent potential for variability in patients' doses, actual usage in a real life setting is not known and needs to be measured beyond an assumption based on the dosages used in clinical trials. This study uses information

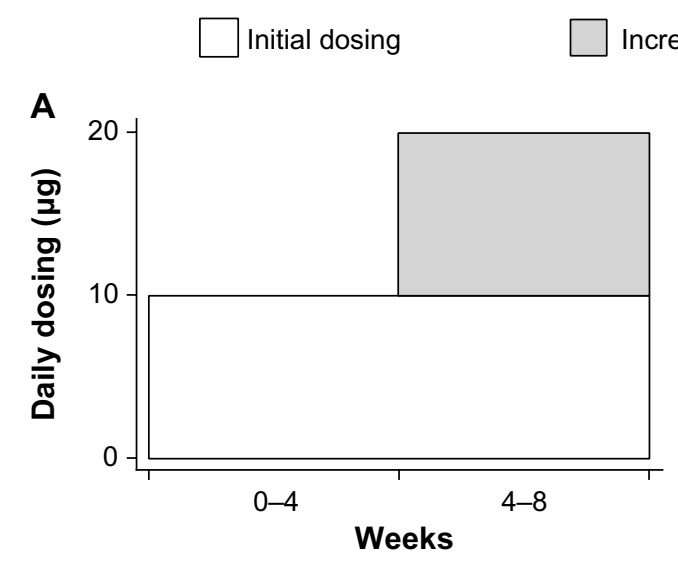

Increased GC

Further increased GC

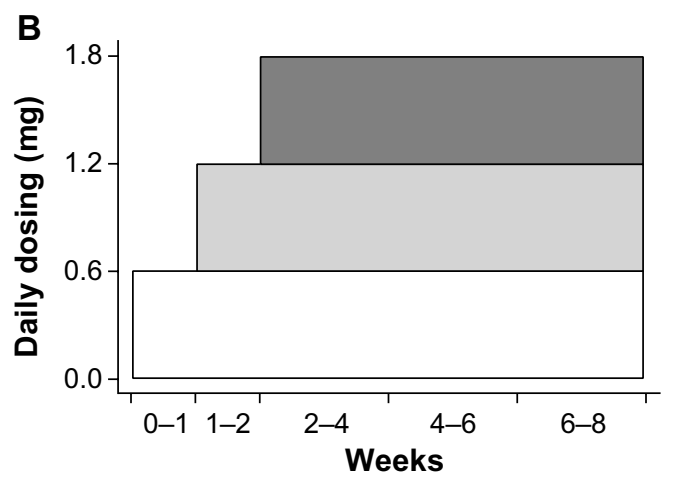

Figure I Dosing titration of exenatide twice daily (A) according to the Summary of Product Characteristics. The dosage for exenatide twice daily can be doubled after 4 weeks if better GC is needed. ${ }^{7}$ The starting dose for liraglutide (B) is $0.6 \mathrm{mg}$ and can be increased after I week to I.2 mg; if better GC is needed, it can be increased to reach $1.8 \mathrm{mg}^{8}$

Abbreviation: GC, glycemic control. 
from administrative pharmacy databases containing data on dispensed prescriptions of the GLP-1 receptor agonist products currently on the market to understand their usage patterns and actual costs in the real world (exenatide once weekly and lixisenatide once daily have obtained marketing authorization more recently in the European Union, but no dispensing data were available within the timeframe of this study). The real world usage observed could then be compared with the clinically established recommended dosage.

The objective of this study was to estimate the average actual usage and real world daily cost of the GLP-1 receptor agonists (exenatide twice daily and liraglutide) in Germany, the Netherlands, and the UK where high-quality data are available. Administrative databases were used to source the data from longitudinal records of dispensed prescriptions. This paper reports the results of analyses conducted to meet this objective.

\section{Materials and methods}

To understand the usage of exenatide twice daily and liraglutide, and the cost of these GLP-1 receptor agonists in a real world setting, the $\mathrm{IMS}^{\circledR}$ Longitudinal Prescription (LRx) database $^{9-11}$ was queried. The relevant data in each country (Germany, the Netherlands, and the UK) were extracted and analyzed according to the study analysis plan developed to address the following research question: within a given country, what is the average usage per day that is being reimbursed for a particular GLP-1 treatment, and what is it costing from a payer perspective?

\section{Data sources}

Unlike the USA, where reimbursement claims datasets cover large populations of patients, there is a dearth of data sources for longitudinal prescription records in Europe. The LRx is a longitudinal database that records details of prescriptions dispensed in pharmacies. It is one of the largest repositories of retail pharmacy data in Europe, available in four countries, ie, Germany, the Netherlands, the UK, and Belgium, at the time of our analyses. However, since this study was conducted, robust LRx data sources have been established in multiple additional European markets. The duration of time that elapsed between both drugs having been launched in Belgium and the data extraction for this study was not considered sufficient to include information from Belgium in the final analyses.

The databases used to build the datasets for these analyses differed between countries, most notably in terms of whether anonymous patients were tracked across pharmacies
(Germany) or within a specific pharmacy only (UK and the Netherlands). Subject to country-specific patient privacy laws, the database in each respective country captures information on the pharmacy (unique identifier [ID] for each pharmacy, prescription date), the product (name, dose, strength, and therapy duration), the prescriber, and the patient (age, sex, and anonymous patient ID in the longitudinal database). At the time of data extraction, the LRx database covered $95 \%$ of national prescribing in Germany and $73 \%$ of national dispensing (ie, what was actually dispensed at the pharmacy) in the Netherlands. In the UK, the Dynamic Prescription database is a variant of the LRx database and captures data on the drug prescribed, the product dispensed, and the prescriber. These data are linked to an anonymous patient ID unique to a specific pharmacy. The Dynamic Prescription database covered $45 \%$ of national prescribing in the UK at the time of data extraction.

\section{Inclusion criteria}

In Germany and the Netherlands, records of prescriptions dispensed to male and female adults were extracted into datasets (one for each country) for analysis according to the following inclusion criteria:

- Patient must have at least two prescriptions for either exenatide twice daily or liraglutide.

- All records were included within a time period such that the date of a patient's first prescription must have been no earlier than the launch date of the drug in that country. Table 1 shows the time span of the data analyzed in the three countries.

- To ensure that patients had previously not received GLP-1 receptor agonist treatment, the first prescription counted as the index date must not have been preceded by a prescription of either exenatide twice daily or liraglutide in the previous 6 months.

The population and dataset resulting after application of these criteria, as well as the attrition flows for Germany and the Netherlands, are presented in Table 1. In the UK, data were subject to additional privacy legislation and were therefore handled (and reported) differently.

\section{Assumptions}

It was assumed that there was $100 \%$ reimbursement in each country, such that the public price was a correct indication of the reimbursement cost per prescription. It was also assumed that any data pertaining to prescriptions of exenatide twice daily and liraglutide are linked to patients with type 2 diabetes. Diagnosis was not specified in the 
Table I Patients meeting inclusion criteria for study

\begin{tabular}{|c|c|c|c|c|c|}
\hline & \multicolumn{3}{|l|}{ Exenatide BID } & \multicolumn{2}{|l|}{ Liraglutide } \\
\hline & Time span of analysis & Patients & Prescriptions & Patients & Prescriptions \\
\hline Germany* & April 7 to May II & 22,232 & 122,756 & 19,395 & 70,075 \\
\hline The Netherlands* & October 7 to May II & 440 & 3,048 & 3,018 & 15,889 \\
\hline \multirow[t]{2}{*}{ UK } & October 8 to June II & 27,326 & 597,930 & 16,272 & 259,278 \\
\hline & & & & Exenatide BID & Liraglutide \\
\hline \multicolumn{6}{|c|}{ Attrition flow in Germany } \\
\hline \multicolumn{4}{|c|}{ Patients in the database } & 47,377 & 46,772 \\
\hline \multicolumn{4}{|c|}{ Patients in the database with at least two prescriptions } & 34,400 & 33,303 \\
\hline \multicolumn{4}{|c|}{ Patients in the database with at least two prescriptions, age information recorded and age $\geq 18$ years } & 34,348 & 33,252 \\
\hline \multicolumn{4}{|c|}{ Patients in the database with at least two prescriptions, known age $\geq 18$ years, sex recorded } & 23,202 & 23,205 \\
\hline \multicolumn{4}{|c|}{$\begin{array}{l}\text { Patients in the database with at least two prescriptions, known age } \geq 18 \text { years, sex recorded, } \\
\text { no prescription of another GLP-I product } 6 \text { months prior to index }\end{array}$} & 23,019 & 19,957 \\
\hline \multicolumn{6}{|c|}{ Attrition flow in the Netherlands } \\
\hline \multicolumn{4}{|c|}{ Patients in the database } & 804 & 4,209 \\
\hline \multicolumn{4}{|c|}{ Patients in the database with no prescription of another GLP-I product 6 months prior to index } & 612 & 4,002 \\
\hline \multicolumn{4}{|c|}{$\begin{array}{l}\text { Patients in the database with no prescription of another GLP-I product } 6 \text { months prior to index } \\
\text { and sex recorded }\end{array}$} & 603 & 3,990 \\
\hline \multicolumn{4}{|c|}{$\begin{array}{l}\text { Patients in the database with no prescription of another GLP-I product } 6 \text { months prior to index } \\
\text { and sex recorded }\end{array}$} & 447 & 3,080 \\
\hline \multicolumn{4}{|c|}{$\begin{array}{l}\text { Patients in the database with no prescription of another GLP-I product } 6 \text { months prior to index, } \\
\text { sex recorded, age information recorded, and age } \geq 18 \text { years }\end{array}$} & 447 & 3,078 \\
\hline
\end{tabular}

Note: *After exclusion of outliers at lower and upper I\% for Germany and the Netherlands, respectively.

Abbreviations: BID, twice daily; GLP-I, glucagon-like peptide-I.

prescription and thus not evident in the database, requiring the assumption that exenatide twice daily and liraglutide are prescribed according to their indication, ie, only to patients with type 2 diabetes. It was assumed that the databases are representative of the national population, with no indication of bias in the selection of the panel from which the data are drawn.

\section{Data handling and analysis}

A descriptive retrospective cohort analysis was conducted to calculate the average daily usage (ADU) and cost of these treatments. Although the actual daily usage cannot be measured directly, the methodology used was aimed at ensuring that the estimates based on dispensed volumes per time period would credibly reflect the true consumption of each drug by typical patients receiving GLP-1 receptor agonists.

Data for Germany and the Netherlands were analyzed in a similar manner, as similar data were available in both countries. To calculate the ADU, all dosages dispensed to each patient, except the last one, were summed. The dosage of the last recorded prescription was not included in the analysis because the length of time for which it was used is unknown. The cumulative dosage was then divided by the number of days between the first and last recorded prescription. The average daily cost (ADC) was calculated by multiplying the estimated ADU by the publicly reimbursed drug price per $\mu \mathrm{g}$ (exenatide) or per mg (liraglutide). These prices are shown in Table 2. Prices are nominal and represent the approved reimbursable amount at the time of sale of the prescription. In the Netherlands, the mean daily cost estimate of exenatide twice daily was based on a weighted average of the $5 \mu \mathrm{g}$ and $10 \mu \mathrm{g}$ packs sold during the timeframe of the analysis, according to the estimated market share proportions of $11.3 \%$ and $88.7 \%$, respectively. ${ }^{12}$ This took into account the difference in the price per $\mu \mathrm{g}$ between the two pack sizes. In Germany, the estimated mean daily cost

Table 2 Public reimbursed prices of exenatide BID and liraglutide in Germany, the Netherlands, and the UK

\begin{tabular}{|c|c|c|c|c|c|}
\hline \multicolumn{3}{|c|}{ Exenatide BID (prefilled pen) } & \multicolumn{3}{|c|}{$\begin{array}{l}\text { Liraglutide (prefilled pen, } \\
6 \mathrm{mg} / \mathrm{mL} \text { ) }\end{array}$} \\
\hline Pack & $\begin{array}{l}\text { Cost } \\
\text { per } \\
\mu \mathrm{g}\end{array}$ & $\begin{array}{l}\text { Cost } \\
\text { per } \\
\text { pack }\end{array}$ & Pack & $\begin{array}{l}\text { Cost } \\
\text { per } \\
\text { mg }\end{array}$ & $\begin{array}{l}\text { Cost } \\
\text { per } \\
\text { pack }\end{array}$ \\
\hline \multicolumn{6}{|l|}{ Germany } \\
\hline $60 \times 5 \mu \mathrm{g} /$ dose & $€ 0.4 \mathrm{I}$ & $€ \mid 23.70$ & $2 \times 3 \mathrm{~mL}$ & $€ 3.44$ & $€ 123.74$ \\
\hline $60 \times 10 \mu \mathrm{g} /$ dose & $€ 0.21$ & $€ \mid 23.70$ & $5 \times 3 \mathrm{~mL}$ & $€ 3.28$ & $€ 294.89$ \\
\hline $180 \times 10 \mu \mathrm{g} /$ dose & $€ 0.20$ & $€ 351.82$ & $10 \times 3 \mathrm{~mL}$ & $€ 3.22$ & $€ 580.15$ \\
\hline \multicolumn{6}{|c|}{ The Netherlands } \\
\hline $60 \times 5 \mu g /$ dose & $€ 0.32$ & $€ 96.20$ & $2 \times 3 \mathrm{~mL}$ & $€ 2.67$ & $€ 96.20$ \\
\hline $60 \times 10 \mu \mathrm{g} /$ dose & $€ 0.16$ & $€ 96.20$ & & & \\
\hline \multicolumn{6}{|l|}{ UK } \\
\hline $60 \times 5 \mu g /$ dose & $£ 0.23$ & $£ 68.24$ & $2 \times 3 \mathrm{~mL}$ & $£ 2.18$ & $€ 78.48$ \\
\hline $60 \times 10 \mu g /$ dose & $€ 0.11$ & $£ 68.24$ & $3 \times 3 \mathrm{~mL}$ & $€ 2.18$ & $£ \mid 17.72$ \\
\hline
\end{tabular}

Notes: Pricing sources: Germany, LRx database;" the Netherlands, IMS Pharmacy Panel; ${ }^{15}$ UK, BNF 63. ${ }^{16}$

Abbreviation: BID, twice daily. 
was based on the actual pack size dispensed at the patient level in the database.

In the UK, information was only available in the form of the number of prescriptions dispensed per pack for both products and the number of patients filling prescriptions per product on a monthly basis. The average monthly usage was calculated for each product by dividing the total volume of product dispensed per month by the number of patients filling prescriptions for the product in that month. The ADU was calculated by dividing the average monthly usage by the number of days in a month. The ADC was calculated by multiplying the ADU by the unit cost (price per mg or $\mu \mathrm{g}$ ) for each product (Table 2). ADC for each product was calculated for the entire period by taking a weighted average of the monthly data.

\section{Outliers}

In Germany and the Netherlands, $1 \%$ of the data was removed from the lower and upper ends of the distribution, respectively (total 2\%). The resulting "trimmed" distributions of estimated daily usage in Germany and the Netherlands are described by the box plot in Figure 2. The considerations, rationale, and methodology for this are described below. Similar handling of outliers was not possible for the UK because access to data was not at the patient level.

Outliers could exist for several reasons, including errors in the recording of data in the databases, and individuals collecting prescriptions on behalf of several patients being recorded as a single patient, thus inflating the calculation of daily usage. There are reasons why ADU estimates based on pharmacy dispensing to an individual patient may plausibly result in a higher dose than medically recommended, especially if a single prescription period is observed. Legitimate fluctuation is caused by a patient collecting his/her prescription at nonregular intervals (eg, stocking up for travel), which the data show as high usage in one period and lower usage in subsequent period(s). Over the entire prescription history of a single patient or in a large patient sample, these temporary fluctuations are expected to even out.

Several cut-off points $(1 \%, 3 \%$, and $5 \%)$ to exclude outliers were explored in order to understand the impact of "trimming" the data for final analysis. It was found that variability (standard deviation) in the data was largely reduced after excluding $1 \%$ of extreme values. This constituted mini-

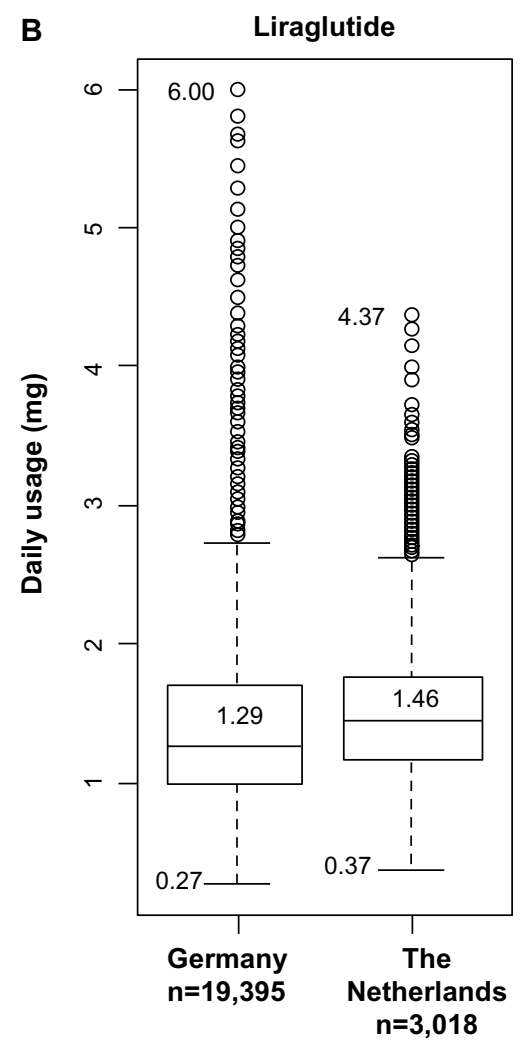

Figure 2 Box plot for the daily usage of exenatide twice daily (A) and liraglutide (B) in Germany and the Netherlands (excluding I\% outliers). Median (trimmed dataset) values are represented by horizontal lines within each box. The upper and lower boundaries of each box represent the upper and lower quartiles, respectively. The upper and lower whiskers represent I.5x the interquartile range. The circles represent data points outside of the whiskers and are defined as outliers. The data label values at both extremes represent the minimum and maximum values. 
mal interference with the original data combined with a high probability of excluding clear data errors. The results are presented for both full and trimmed datasets from Germany and the Netherlands. However, all study conclusions are based on results using the trimmed data.

In Germany, the average daily usage $\left(\mathrm{ADU}_{\mathrm{n}}\right)$ was calculated for each patient's 1st, 2nd, 3rd, 4th ....... (n-1) ${ }^{\text {th }}$ prescription and then estimated globally (ADU) across all prescriptions. In order to identify the extreme values in the dataset, all prescription records were ranked by the $\mathrm{ADU}_{\mathrm{n}}$. Following the inspection of the $\mathrm{ADU}_{\mathrm{n}}$ distribution, $1 \%$ of observations at the low and high ends of the distribution, respectively, were removed as outliers.

In the Netherlands, the LRx database had an automatic algorithm for detecting extreme values in the dataset, which were then removed manually. Extreme values at the patient level were defined as individuals with extreme numbers of prescriptions $(>100)$ or units of product $(>500)$ per month. A pharmacy could be excluded in a particular month if it dispensed twice its historical amount of monthly prescriptions. Thus, there were very few extreme values in the dataset at the time of analysis. For the $1 \%$ cut-off extreme values, patients were ranked based on overall ADU (per patient). Patients with extreme ADU values at both the low and high ends of the distribution were removed.

Data handling and analyses were carried out using the following software packages: Microsoft Excel ${ }^{\circledR} 2003$ and 2007 (Redmond, WA, USA), R version 2.13.1, and Statistical Analysis System version 9.2 (SAS Institute Inc, Cary, NC, USA).

\section{Results}

The results of this study are based on analyses of data linked to prescriptions of exenatide twice daily and liraglutide dispensed in Germany, the Netherlands, and the UK during a time period spanning April 2007 to June 2011 (Table 1). The German database comprised 22,232 patients who received 122,756 prescriptions of exenatide twice daily and 19,395 patients who received 70,075 prescriptions of liraglutide. In the Netherlands, 440 patients received 3,048 exenatide twice daily prescriptions and 3,018 patients received 15,889 liraglutide prescriptions. The UK database captured 27,326 exenatide twice daily patients and 16,272 liraglutide patients who received 597,930 and 259,278 prescriptions, respectively.

The ADU of exenatide twice daily was estimated to be $16.81 \mu \mathrm{g}, 17.07 \mu \mathrm{g}$, and $20.49 \mu \mathrm{g}$ for Germany, the Netherlands, and the UK, respectively, whereas the estimated mean daily usage of liraglutide was $1.37 \mathrm{mg}, 1.49 \mathrm{mg}$, and $1.50 \mathrm{mg}$ for Germany, the Netherlands, and the UK, respectively (Table 3 ).

Table 3 shows the impact of excluding outliers from the German and Dutch datasets. Removal of $1 \%$ of extreme values from both ends of the distribution reduced the estimated mean exenatide twice daily usage from $19.06 \mu \mathrm{g}$ to $16.81 \mu \mathrm{g}$ and from $19.37 \mu \mathrm{g}$ to $17.07 \mu \mathrm{g}$ for Germany and the Netherlands, respectively. The corresponding reduction in mean liraglutide usage was from $1.52 \mathrm{mg}$ to $1.37 \mathrm{mg}$ for Germany and from $1.56 \mathrm{mg}$ to $1.49 \mathrm{mg}$ for the Netherlands. Data for the UK are missing from Table 3 due to similar handling of outliers not being possible for the UK (as stated in the Materials and methods section above). The remaining

Table 3 Estimated average daily usage and cost of exenatide BID and liraglutide in Germany, the Netherlands, and the UK for total sample and excluding $1 \%$ of outliers

\begin{tabular}{|c|c|c|c|c|c|c|c|c|c|c|c|}
\hline \multirow{3}{*}{$\begin{array}{l}\text { Patient } \\
\text { group }\end{array}$} & \multicolumn{4}{|c|}{ Germany } & \multicolumn{4}{|c|}{ The Netherlands } & \multicolumn{3}{|l|}{ UK* } \\
\hline & \multirow[t]{2}{*}{$\mathbf{n}$} & \multicolumn{2}{|c|}{ Daily usage } & \multirow{2}{*}{$\begin{array}{l}\text { Daily } \\
\text { cost } \\
\text { Mean } \\
\text { (SD) }\end{array}$} & \multirow[t]{2}{*}{$\mathbf{n}$} & \multicolumn{2}{|c|}{ Daily usage } & \multirow{2}{*}{$\begin{array}{l}\text { Daily } \\
\text { cost } \\
\text { Mean } \\
\text { (SD) }\end{array}$} & \multirow[t]{2}{*}{$\mathbf{n}$} & \multirow{2}{*}{$\begin{array}{l}\text { Daily } \\
\text { usage }\end{array}$} & \multirow{2}{*}{$\begin{array}{l}\text { Daily } \\
\text { cost }\end{array}$} \\
\hline & & $\begin{array}{l}\text { Mean } \\
(\mathrm{SD})\end{array}$ & $\begin{array}{l}\text { Median } \\
(\min / \max )\end{array}$ & & & $\begin{array}{l}\text { Mean } \\
(\mathrm{SD})\end{array}$ & $\begin{array}{l}\text { Median } \\
(\min / \max )\end{array}$ & & & & \\
\hline \multicolumn{12}{|c|}{ Exenatide BID } \\
\hline All patients & 23,019 & $\begin{array}{l}19.06 \mu \mathrm{g} \\
(28.46)\end{array}$ & $\begin{array}{l}17.3 \mid \mu \mathrm{g} \\
(0.26 / 1,800.00)\end{array}$ & - & 447 & $\begin{array}{l}19.37 \mu \mathrm{g} \\
(32.81)\end{array}$ & $\begin{array}{l}17.40 \mu \mathrm{g} \\
(2.19 / 600.00)\end{array}$ & - & 27,326 & $20.49 \mu \mathrm{g}$ & $£ 2.53$ \\
\hline $\begin{array}{l}\text { Excluding I\% } \\
\text { of outliers }\end{array}$ & 22,232 & $\begin{array}{l}16.81 \mu g \\
(6.82)\end{array}$ & $\begin{array}{l}\text { I7.14 } \mu \mathrm{g} \\
(2.27 / 75.00)\end{array}$ & $€ 4.02$ & 440 & $\begin{array}{l}17.07 \mu \mathrm{g} \\
(9.93)\end{array}$ & $\begin{array}{l}17.40 \mu \mathrm{g} \\
(2.68 / 100.00)\end{array}$ & $€ 3.05$ & - & - & - \\
\hline \multicolumn{12}{|l|}{ Liraglutide } \\
\hline All patients & 19,957 & $\begin{array}{l}1.52 \mathrm{mg} \\
(2.28)\end{array}$ & $\begin{array}{l}1.29 \mathrm{mg} \\
(0.06 / / 80.00)\end{array}$ & - & 3,078 & $\begin{array}{l}1.56 \mathrm{mg} \\
(1.57)\end{array}$ & $\begin{array}{l}1.46 \mathrm{mg} \\
(0.18 / 72.00)\end{array}$ & - & 16,272 & $1.50 \mathrm{mg}$ & $£ 3.28$ \\
\hline $\begin{array}{l}\text { Excluding I\% } \\
\text { of outliers }\end{array}$ & 19,395 & $\begin{array}{l}1.37 \mathrm{mg} \\
(0.58)\end{array}$ & $\begin{array}{l}1.29 \mathrm{mg} \\
(0.27 / 6.00)\end{array}$ & $€ 4.54$ & 3,018 & $\begin{array}{l}\mathrm{I} .49 \mathrm{mg} \\
(0.5 \mathrm{I})\end{array}$ & $\begin{array}{l}\text { I. } 46 \mathrm{mg} \\
(0.37 / 4.37)\end{array}$ & $€ 3.97$ & - & - & - \\
\hline
\end{tabular}

Notes: *Median values unavailable for the UK due to compliance with information privacy legislation in the UK which restricts access to individual patient-level data. Abbreviations: BID, twice daily; min, minimum; max, maximum; SD, standard deviation. 
analyses were conducted using the "trimmed" databases for Germany and the Netherlands.

The mean daily cost for Germany was estimated to be $€ 4.02$ for exenatide twice daily and $€ 4.54$ for liraglutide. For the Netherlands, the ADC was $€ 3.05$ for exenatide twice daily and $€ 3.97$ for liraglutide. These findings correspond to a mean daily difference in price of $€ 0.52$ per patient in Germany and $€ 0.92$ per patient in the Netherlands. The ADC for the UK was $£ 2.53$ and $£ 3.28$ for exenatide twice daily and liraglutide, respectively (a difference of $£ 0.75$ ) (Table 3 ).

\section{Discussion}

This study estimated the real world usage and cost of exenatide twice daily and liraglutide, the earliest GLP-1 receptor agonists available, in Germany, the Netherlands, and the UK, ie, countries where high-quality data are available. This type of evidence from real life clinical practice provides useful insight and adds to the evidence base needed to inform health technology assessment as the number of GLP-1 receptor agonists available increases. The estimates of ADU are based on dispensed volumes of drugs during a specified period of time because it is difficult to observe the actual dose prescribed or the actual dose taken by patients.

Small differences were observed in the mean daily usage estimated for both exenatide twice daily and liraglutide in the different countries. The ADU for exenatide twice daily was lower in Germany and the Netherlands compared with that in the UK. For liraglutide, on the other hand, mean daily usage was slightly lower in Germany than in the Netherlands and the UK. Factors affecting dose selection, such as efficacy or tolerability, were not explored in this study.

Some of the daily usage estimates were unexpectedly high. Generally, one assumes that patients may miss doses or take a lower dosage periodically, and therefore the majority of daily usage estimates should be below the recommended dosage. In these pharmacy reports, some of the daily usage was well above the recommended dosages. While this may reflect misuse of these GLP-1 receptor agonists, perhaps to increase weight loss or due to stockpiling, error in the reporting system is also possible. It is not possible to separate errors in the reporting system from true usage, so a cut-off of $1 \%$ was used to remove outliers; this minimized interference with the data while removing clear outliers likely resulting from reporting errors (eg, values at multiple times the recommended daily dosage).

Mean daily costs were calculated based on mean daily usage estimates and the publicly reimbursed prices of the drugs in the respective countries. The daily cost of exenatide twice daily was estimated to be lower than that of liraglutide in all three countries. It is worth noting that this study was completed prior to approval of exenatide once weekly, so the estimated cost and daily dose of exenatide twice daily are neither influenced by nor generalizable to exenatide once weekly.

Using dispensing data from pharmacy administrative databases, this study yielded estimates of the mean daily usage of two medications and their cost in three countries despite inherent differences in national treatment practice, prescribing patterns, and the method of data collection. To the authors' knowledge, this is the first study to estimate the actual daily usage of exenatide twice daily and liraglutide based on quantities dispensed in various countries. The estimates of mean daily usage of the two medications in the three countries appear to be fairly reasonable considering both the large sample size and the distribution of data (Figure 2). Estimates of mean daily cost, based on national retail prices and estimated ADU, allowed for comparison of the costs of exenatide twice daily and liraglutide in the German, Dutch, and UK health care settings. Based on the estimated real life mean daily doses, the cost of exenatide therapy appears to be systematically lower in all of the countries included in this study (Table 3). The analyses leading to these results were based on a number of assumptions, which is a limitation of this study. Because a diagnosis was not specified in a prescription record, exenatide twice daily and liraglutide were assumed to be prescribed only for patients with type 2 diabetes and according to their product labeling. Further, the LRx databases in the individual countries were built according to preset rules and algorithms to ensure that records were complete for analysis, which included the removal of incomplete records and extreme outliers before the current analysis was conducted. It was not feasible to view records that were removed prior to analysis; however, there was no reason to assume that the occurrence of incomplete records or extreme outliers would be unevenly distributed between the exenatide twice daily and liraglutide arms. Finally, the assumption of $100 \%$ reimbursement affects the projected health care costs for each drug; however, attempting to incorporate reimbursement rates into the analyses would have required more complex assumptions.

The UK dataset was limited to aggregated data, meaning that the UK analysis was based on the aggregated number of prescriptions and the number of patients filling prescriptions on a monthly basis. We assumed that each prescription was equal to one pack of the drug and that the patients were 
generally loyal to their pharmacy, as the anonymous patient ID was linked to one pharmacy only. Aggregated data did not allow the scrutiny of potential outliers in the same way as was done using patient-level data for Germany and the Netherlands. This reduced the comparability of results between countries, but constituted, however, the best available estimate of daily cost of GLP-1 receptor agonists in the UK.

Another limitation of the study was the uncertainty surrounding the sources of outliers in the German and Dutch data. It is unknown whether the outliers were errors in reporting, patient stockpiling, patients collecting prescriptions on behalf of several patients, or true data. However, given the impossibility of knowing the cause of outliers, $1 \%$ of the highest and lowest records were removed, which served to reduce the variability of the estimated daily usage. In addition to the database-specific quality checks described above, we believe the $1 \%$ trimming minimized the risk of errors in the data. Patient stockpiling or accidental loss of dispensed medication is less likely to bias estimates as these would even out in a large sample, and from the health care payer's perspective these are relevant usage-related costs.

Real world usage and cost estimates are highly relevant to health care decision-makers when assessing the financial impact of a new class of drugs. The relevance of data on real world usage was demonstrated by the Dutch example. According to the publicly available reimbursement decision on liraglutide in the Netherlands, the proposed standard daily dosages were $1.2 \mathrm{mg} /$ day for liraglutide and $10 \mu \mathrm{g}$ twice daily for exenatide, which should not result in a cost difference between these two therapies. However, based on the real life daily doses being dispensed to patients, the mean cost of exenatide therapy appeared to be lower.

The daily dosing of liraglutide in Germany was reported in a conference poster by Fuchs et al. ${ }^{13}$ The mean daily dosage for patients initiating therapy with liraglutide between July 2009 and November 2010 was estimated to be $1.42 \mathrm{mg}$ (1.29 $\mathrm{mg}$ after excluding outliers [3\% from both the upper and lower bounds]). These estimates are lower than what was observed in the current study. However, it is inappropriate to compare results, given that both the research question and the methodology used to define the daily dosage appear to be different. Further, the inclusion criteria, such as requirement for length of time on therapy and the time period of the study, were not published.

It should be emphasized that pharmacy cost alone is not the only criterion for optimal choice of therapy. Real world clinical effectiveness and the total cost of outcomes of alternative treatments must be taken into account. Fewer diabetes complications would be expected to decrease health care utilization and costs. Exenatide twice daily was the first GLP-1 receptor agonist to be marketed. Since its availability, a number of studies in the US setting have demonstrated that treatment outcomes experienced by patients in real world clinical practice are consistent with results from clinical trials. ${ }^{14}$ This observation cannot, however, be extrapolated to other drugs in the same class without the accompanying research in terms of real world outcomes.

Further research in this area should include the ongoing analysis of country-level data because usage may vary within different health systems and over time. Further, while this analysis focused on daily usage over the entire study period, it would be interesting to observe trends in dose escalation over time for drugs in the GLP-1 receptor agonist class. Moreover, as experience in using methods for estimating drug usage in real world setting accumulates, it would be worthwhile applying these methods to investigate more complete and more complex therapies, such as insulin regimens and combination therapies. The next step to build on this work could include outcomes research on the effectiveness of the two agents and validation of the study population being estimated. A description of the baseline characteristics and demographics of the study population covered, as well as validation of patient numbers, would be necessary to be able to extrapolate the results to the national population.

\section{Conclusion}

This study adds to the literature on type 2 diabetes and GLP-1 receptor agonists by estimating the daily usage and costs of treatment with exenatide twice daily and liraglutide in the real world setting. Despite country-specific differences in databases, prescribing and dispensing practices, the assumptions made, and the limitations of the methodology used, this study demonstrates that real world estimates of average daily dispensed doses of GLP-1 receptor agonist inhibitors derived from pharmacy data correspond reasonably well to the dosages recommended by the summaries of product characteristics, given the titration schedule for each product. The only exception was the estimated mean daily usage of exenatide twice daily in the UK, which exceeded the recommended maximum dose by $0.49 \mu \mathrm{g}$; this result could have been affected by the inability to analyze outliers, as only the average monthly data were available in the UK. In all three countries, the mean daily cost of exenatide twice daily was lower than that of liraglutide. Based on these 
estimated dosages, exenatide twice daily appeared to cost on average $€ 0.52, € 0.92$, and $£ 0.75$ less per day than liraglutide in Germany, the Netherlands, and the UK, respectively.

\section{Acknowledgment}

The authors thank Mary Beth DeYoung of AstraZeneca for critical review and useful editorial suggestions.

\section{Disclosure}

This research was conducted by IMS Health with sponsorship by Eli Lilly and Company. This article was prepared by IMS Health with guidance from Eli Lilly and Company and reviewed by AstraZeneca. AstraZeneca provided funding for editorial revisions of this manuscript by inScience late in its development. Amanda L McDonell, Robert W Kotchie, and Thomas Haslam are employed by IMS Health. Per-Olof Thuresson, Michiel Bruinsma, and Danielle C Zammit were employed by IMS Health at the time of the study. Thorsten Otto is employed by Eli Lilly and Company, Germany. Urpo Kiiskinen and Claudia Nicolay are employed by and are stock shareholders of Eli Lilly and Company, Germany. AnneJeanine Janszen-Van Oosterhout was employed by and was a stock shareholder of Eli Lilly Nederland, the Netherlands, at the time of the study. The authors report no other conflicts of interest in this work.

\section{References}

1. World Health Organization. Fact sheet No 312 - Diabetes. Geneva, Switzerland: World Health Organization; 2011. Available from: http:// www.who.int/mediacentre/factsheets/fs312/en/. Accessed December 19, 2013.

2. International Diabetes Federation. IDF Diabetes Atlas. 6th ed. Brussels, Belgium: International Diabetes Federation; 2013. Available from: http:// www.idf.org/diabetesatlas. Accessed December 19, 2013.
3. Jonsson B; CODE-2 Advisory Board. Revealing the cost of type II diabetes in Europe. Diabetologia. 2002;45(7):S5-S12.

4. International Diabetes Federation Clinical Guidelines Task Force. Global guideline for type 2 diabetes. Brussels, Belgium: International Diabetes Federation; 2005. Available from: http://www.idf.org/globalguideline-type-2-diabetes-2005. Accessed December 19, 2013.

5. Inzucchi SE, Bergenstal RM, Buse JB, et al. Management of hyperglycemia in type 2 diabetes: a patient-centered approach: position statement of the American Diabetes Association (ADA) and the European Association for the Study of Diabetes (EASD). Diabetes Care. 2012;35(6):1364-1379.

6. Buse JB, Rosenstock J, Sesti G, et al. Liraglutide once a day versus exenatide twice a day for type 2 diabetes: a 26 -week randomised, parallel-group, multinational, open-label trial (LEAD-6). Lancet. 2009;374(9683):39-47.

7. European Medicines Agency. Summary of Product Characteristics Byetta. 2013. Available from: http://www.ema.europa.eu/docs/en_GB/ document_library/EPAR_-_Product_Information/human/000698/ WC500051845.pdf. Accessed December 19, 2013.

8. European Medicines Agency. Summary of Product Characteristics Victoza. 2013. Available from: http://www.ema.europa.eu/docs/en_GB/ document_library/EPAR_-_Product_Information/human/001026/ WC500050017.pdf. Accessed December 19, 2013.

9. IMS Xponent Dynamic Prescription Data (Oct 2008-Jun 2011). UK: Proprietary IMS data on file; 2011.

10. IMS Xponent Longitudinal Prescription Data (Oct 2007-May 2011). The Netherlands: Proprietary IMS data on file; 2011.

11. IMS Xponent Longitudinal Prescription Data (Apr 2007-May 2011). Germany: Proprietary IMS data on file; 2011.

12. IMS Sales Data. IMS; 2011.

13. Fuchs S, Kostev K, Seitz L, Wohlleben M. Ermittlung der tatsächlichen Tagesdosierung von Liraglutid (PDD) unter realen Versorgungsbedingungen im Hinblick auf die Berechnung von Tagestherapiekosten [Identification of the Prescribed Daily Dose (PDD) using the example of Liraglutide with regard to defining daily therapy costs]. 46. Jahrestagung der Deutschen-Diabetes-Gesellschaft [46th Annual Meeting of the German Diabetes Society]; June 1-4, 2011, Leipzig, Germany.

14. Best JH, Lavillotti K, DeYoung MB, Garrison LP. The effects of exenatide bid on metabolic control, medication use and hospitalization in patients with type 2 diabetes mellitus in clinical practice: a systematic review. Diabetes Obes Metab. 2012;14(5):387-398.

15. IMS Pharmacy Panel (The Netherlands). IMS Health; 2011.

16. Royal Pharmaceutical Society. MedicinesComplete. Available from: https://www.medicinescomplete.com Accessed March 19, 2012.
ClinicoEconomics and Outcomes Research

\section{Publish your work in this journal}

ClinicoEconomics \& Outcomes Research is an international, peerreviewed open-access journal focusing on Health Technology Assessment, Pharmacoeconomics and Outcomes Research in the areas of diagnosis, medical devices, and clinical, surgical and pharmacological intervention. The economic impact of health policy and health systems

\section{Dovepress}

organization also constitute important areas of coverage. The manuscript management system is completely online and includes a very quick and fair peer-review system, which is all easy to use. Visit http://www.dovepress.com/testimonials.php to read real quotes from published authors. 